\title{
Heckscher-Ohlin theory when countries have different technologies
}

\author{
Eric O'N. Fisher
}

\begin{abstract}
A B S T R A C T
Rethinking the foundations of Heckscher-Ohlin theory when countries have different technologies, this paper shows how to make the proper adjustments for international productivity differences. The central tool is a factor conversion matrix that computes the local factor content of foreign Rybczynski effects. Factor-specific productivities are a special case of these more general linear relationships.
\end{abstract}

\section{Introduction}

Heckscher-Ohlin theory is codified by four central propositions. The first is the Heckscher-Ohlin Theorem itself; a country tends to export the goods that use intensively the factors with which it is abundantly endowed. The second is the Factor Price Equalization Theorem; international trade tends to bring factor prices closer together, and thus a locally abundant factor that is globally scarce will benefit from trade. The third is the Stolper-Samuelson Theorem; changes in goods prices magnify changes in factor prices. The fourth is the Rybczynski Theorem; at fixed factor goods prices and thus fixed factor prices, changes in endowments magnify changes in outputs.

In my opinion-and perhaps that of Samuelson (1953) too-the deepest aspect of Heckscher-Ohlin theory is the reciprocity relationship inherent in the duality between the Stolper-Samuelson and the Rybczynski Theorems. An economy's Rybczynski effects are described by the Hessian of its national revenue function, and its Stopler Samuelson effects are just the transpose of that matrix. When one speaks of the effect that a rise in the price of apples has on the wage rate, one is also describing how the supply of apples will change when the supply of workers increases, when factor prices are fixed.

But a Rybczynski effect is really a local effect. It depends on the local technology, and it has nothing to do with international trade per se. There is nothing in trade theory requiring-and there is absolutely no empirical evidence suggesting-that countries have identical technologies. So the simplest form of the Heckscher-Ohlin paradigm that we teach routinely is an uninteresting theoretical construct with no empirical foundation.

Once one admits that countries have different technologies, then the fundamental question becomes, "How can one best describe factor productivity differences between countries?" The usual tack is to posit factor-specific technical differences or Hicks-neutral total factor productivity differences or a combination of both. None of these adjustments is general in theory, and none of them actually works empirically. So the whole field is searching for an elegant way to describe these differences.

I characterize them using factor conversion matrices. They are a generalization of the insight of Brecher and Choudhri (1982), who described a model with three goods and two factors where all goods were produced. They noted that goods prices would adjust so that every good would be produced for a given set of factor prices. Helpman (1984) extended their work, and I will show 
how it generalizes. But the key insight is that typically many of the same goods are produced and traded in every country. This fact implies that there is an interesting and empirically robust relationship between factor prices and technologies in different countries.

Here is how one constructs a factor conversion matrix. Consider an increase in the foreign endowment when goods prices are fixed. This increment will give rise to marginal changes in the vector of foreign output. Then compute the local factor content of these foreign Rybczynski effects. This linear mapping is the factor conversion matrix.

Here is another interpretation of a factor conversion matrix. My work starts from the presumption that trade equalizes goods prices, but it will not equalize factor prices except in the most unusual circumstances. One is immediately interested in how local factor prices translate into foreign ones. The answer to this question is the transpose of the factor conversion matrix.

One way to reconcile Heckscher-Ohlin theory with the data is to use the artifice of Fisher and Marshall (2008) of a virtual endowment. This construct begins by choosing a reference country. Then it takes the actual output of each country and computes the factors that would be necessary to produce that output using the technology of the reference country. In essence, a list of virtual endowments assumes that the assumptions of classical trade theory hold true, when technologies and factor prices are identical to those of the reference country. Using these virtual endowments, one makes a theoretical prediction about the factor content of trade measured according to the reference country's technology. In empirical applications, this construct works remarkably well.

In fact, there is a deep relationship between a country's virtual endowment and the factor conversion matrix. A country's virtual endowment is its productivity-adjusted actual endowment plus an error term that depends on the reference country's technology. The local factor content of this error term is zero, but its factor content in the reference country may differ from zero.

The rest of this paper is structured as follows. In the second section, I will sketch out the preliminaries and describe the factor price non-equalization relationship. The third section explores more deeply what factor content really means when countries have different technologies. The fourth section gives a series of increasingly complex examples showing the usefulness of the factor conversion matrices. The fifth section presents some brief conclusions and an exhortation for future research.

\section{Preliminaries}

There are $n$ goods and $f$ factors. Let the $f \times 1$ vector $w$ denote factor prices. The description of production is an $n \times f$ technology matrix:

$A(w)$

whose rows correspond to goods and columns to factors. The canonical element $a_{i j}$ denotes the unit input requirement of factor $j$ in the production of good $i$. In classical trade theory, the mapping $A(\cdot)$ is assumed to be identical for all countries. For fixed factor prices, the rows of $A(w)$ define factor uses for each good, and these rows generate the diversification cone. If the economy's endowment lies in that cone, then it can produce positive amounts of all goods and employ its factors fully. If there are more goods than factors, then there is an $n-f$ dimensional subspace of output that satisfies the full employment condition (when $n>f$ and the technology matrix has full rank).

Some authors such as Schott (2003) and Romalis (2004) have emphasized that countries seem to produce goods in different cones of diversification. In essence, countries produce different goods depending upon their factor endowments. This is a plausible explanation for the lack of factor price equalization that is obvious in the data, but it ignores the important fact that countries produce and trade every good, defined at the level of aggregation for the data used in empirical studies. It may be the case that countries produce a particular good using very different techniques, but it is not true that countries trade different subsets of goods. The taxonomy of macroeconomic accounts is just too coarse readily to confirm these ideas.

The columns of $A(w)$ have an interesting interpretation too. They define a region that I shall call the goods price diversification cone. If commodity prices $p$ lie in that region, then there are non-negative factor prices $w$ such that

$$
A(w) w=p .
$$

There is an extensive empirical literature showing that countries have different technologies. Implicit in that literature is the fact that countries manage to produce (and trade) almost every good at the usual level of aggregation for national accounts. The empirical literature that emphasizes that countries produced in different cones of diversification tends to ignore this important empirical fact. Perhaps it is more appropriate to state that this literature implicitly assumes that countries actually produce different goods, even though they are classified as identical in national income accounts.

\subsection{Common prices}

It is natural to study a model where

$$
A_{i}\left(w_{i}\right) w_{i}=p=A_{j}\left(w_{j}\right) w_{j}
$$


where perhaps $A_{i}(\cdot) \neq A_{j}(\cdot)$ or $w_{i} \neq w_{j}$ or both. If the former is true, then we are assuming that the two countries have fundamentally different technologies, and if the latter is true, then we are abandoning the assumption of uni-valence explored by Gale and Nikaido (1965), Chipman (1969), and others. This equation is a formalization of the observation of Schott (2004) that countries almost never specialize at an industry level.

I hope it is not too much of a distraction to call the relationship in Eq. (1) the phenomenon of factor price non-equalization. This equation captures what I consider the two most salient aspects of the data: (1) countries' technologies are different; and (2) all goods are produced and traded everywhere. I would argue that the main hindrance to a more complete understanding of Heckscher-Ohlin theory has been an undue fixation on factor price equalization and the assumption of identical technologies. My aim in this paper is to free the profession from these psychological fetters.

Let us assume that both countries are competitive in all goods; this is equivalent to assuming that the intersection of the two goods price diversification cones is not empty. In particular, I am assuming that for some goods prices $p$, there exist local factor prices such that the two systems of equations implicit in Eq. (1) have a solution.

Eq. (1) pushes the logic of Berhhofen (2009) to the extreme; it underscores that tests based upon countries being in different endowment diversification cones may not be warranted. Studying unit values for highly disaggregated goods, Schott (2004) and Hallak (2006) both might argue that there are systematic quality differences in some goods classified as identical in trade statistics. Of course, Eq. (1) is a statement about prices, not unit values. Also, this equation abstracts from trade costs, but Fisher and Marshall (2008) have shown that these costs are not a significant deterrent to trade at the two-digit level of aggregation.

Consider fixed Leontief technology matrices $A_{i}$ and $A_{j}$. The set of possible world prices that allow every good to be produced in both countries is the intersection of two $f$-dimensional cones defined by column spaces of $A_{i}$ and $A_{j}$. For a fixed $p$ in that sub-space,

$$
w_{i}=A_{i}^{+} p+\left(I-A_{i}^{+} A_{i}\right) z_{i}
$$

for some $z_{i} \in R^{f}$. In this expression $A_{i}^{+}$is the Moore-Penrose pseudo-inverse of the technology matrix of Country $i$.

It is important to emphasize that this expression gives the set of all possible factor prices in Country $i$ that are consistent with the observed goods prices $p$. It consists of a particular solution and a homogeneous term. The homogeneous term $I-A_{i}^{+} A_{i}$ is the aspect of local factor prices that has nothing to do with goods prices. This term can differ from zero only if there are more factors than goods or if the local technology matrix is not of full rank. If $f>n$, then local factor supplies usually pin down factor prices. (These kinds of considerations are of course extraneous in a study of the relationship between goods prices and factors prices.) If the local technology matrix does not have full rank, then either at least two goods use all factors in the same proportions or two factors are used by all industries in the same proportions. Both of these cases are of little general interest to a trade theorist, and I will not pursue them in this paper. Indeed, it is often the case that

$$
I-A_{i}^{+} A_{i}=0,
$$

a fact that I will assume in the rest of my discussion. It is certainly true in almost all empirical applications, since macroeconomic accounts usually record a much larger number of goods than factors.

Comparing factor productivities across countries is essentially the study of factor price differences. There is no elegant way to model factor productivity differences across countries, but the fact that almost every country seems to be able to produce almost every good and trade it on world markets has important implications for trade theory. Since $p=A_{j} w_{j}$

$$
w_{i}=A_{i}^{+} A_{j} w_{j}+\left(I-A_{i}^{+} A_{i}\right) z_{i} .
$$

Fisher and Marshall (2008) call the transpose of the $f \times f$ matrix $A_{i}^{+} A_{j}$ in Eq. (2) the factor conversion matrix.

Each column of $A_{i}^{+} A_{j}$ shows how the corresponding factor price in Country $j$ maps onto all the factor prices in Country $i$. The factor conversion matrix is a linear mapping, and it takes into account how the factor uses in Country $j$ project most immediately onto those in Country $i$. The idea of Leontief (1953) of factor-specific technical differences corresponds to the special case where the factor conversion matrix is diagonal. In empirical applications, its off-diagonal elements are large, and there is no theoretical reason to restrict it in this manner.

\subsection{Local prices differ}

Imagine that each country had different local technologies and different local prices. ${ }^{1}$ Trade costs or idiosyncratic local monopoly markups might still allow prices to be roughly comparable across borders. We could consider a model where

$$
p_{i}+u_{i}=p=p_{j}+u_{j}
$$

where $p_{i}$ are local prices, $u_{i}$ is akin to measurement error and $p$ are common world prices. Then

$$
w_{i}=A_{i}^{+} A_{j} w_{j}+A_{i}^{+} v_{i j}
$$

where $v_{i j}=-u_{i}+u_{j}$. Eq. (3) states that factor prices in Country $j$ can be related bilaterally with those in Country $i$, up to some

\footnotetext{
${ }^{1}$ This subsection was inspired by a referee's comments.
} 
measurement error that depends upon local conditions in each country. In the usual case where $n>f$ and $A_{i}$ has full rank, the pseudo-inverse has a simple formula

$$
A_{i}^{+}=\left(A_{i}^{T} A_{i}\right)^{-1} A_{i}^{T},
$$

the projection matrix used by econometricians. Hence $A_{i}^{+} A_{j}$ is given by estimating a system of seemingly unrelated regressions without constants. Each column of $A_{j}$-representing a factor's use in every sector in Country $j$-is regressed against all the factor uses in every sector in Country $i$. The coefficients from this regression form the column of $A_{i}^{+} A_{j}$ that shows how a factor price in Country $j$ maps onto all the factor prices in Country $i$.

The residuals from those regressions are estimates of how important bilateral price differences are for factor productivity comparisons. Since the seemingly unrelated regressions all have the same right hand variables-the technology matrix of Country $i$-ordinary least squares is consistent. Hence one could get a sense of how important deviations of local prices from world prices are in determining factor productivity differences across pairs of countries. This exercise has a little of the flavor of what Davis and Weinstein (2001) have done, but it uses all the information in two countries technology matrices to estimate the $f^{2}$ parameters that completely characterize productivity differences in a linear system. This is the technique that Fisher and Marshall (2008) use to solve the mystery of missing trade.

\section{What does factor content really mean?}

If countries produce and manage to trade every good in spite of having fundamentally different technologies, then local technologies adapt to international economic conditions, at least in the long run. But then the services of a unit of capital in the local economy may have very little to do with those of a trading partner. Hence the very definition of the factor content becomes problematic.

Let $y_{i}$ be the output vector produced in Country $i$. Its local factor content is

$$
v_{i}=A_{i}^{T} y_{i}
$$

where $v_{i}$ is the local vector of endowments and where we have imposed the full employment condition. But what the factor content of this output vector from the point of view of some reference country 0 ? It is natural to define:

$$
\tilde{v}_{i}=A_{0}^{T} y_{i}
$$

Notice that the reference country's virtual endowment is its actual endowment. The same fact is true for any country that has a technology identical with that of the reference country. Fisher and Marshall (2008) define $\tilde{v}_{i}$ as Country $i$ 's virtual endowment when the technology matrix $A_{0}$ is the reference. Using a reference country allows meaningful international comparisons of factor services. In essence it answers this question, What would the endowments of every country be if the world actually satisfied the assumptions of Heckscher-Ohlin theory and were viewed through the lens of a reference country's technology?

There is nothing radical about this definition. For example, Davis and Weinstein (2001) begin their exploration of the factor content by defining a world average technology matrix, a concept that has little theoretical coherence. Any author trying to test the Heckscher-Ohlin theory has to come up with some proxy for a world technology, and we are using a definition that is theoretically cogent and also rationalizes the data.

A virtual endowment can be related to the factor conversion matrix. Since $A_{i}^{T} y_{i}=v_{i}$, we may write

$$
y_{i}=\left(A_{i}^{T}\right)^{+} v_{i}+\left(I-\left(A_{i}^{T}\right)^{+} A_{i}^{T}\right) z_{i}
$$

for some $z_{i} \in R^{n}$. In the usual empirical case where the number of goods exceeds the number of factors, the actual output $y_{i}$ may not correspond to the particular solution in Eq. (4), but any difference will have a net local factor content of zero. The economic intuition is that every production possibility frontier in an economy with more goods than factors will have flats along which the factor content of any output vector is identical. The mathematics follows from the fact that the homogeneous part of Eq. (4) projects onto the null space of $A_{i}^{T}$ so the term $z_{i}$ uses no extra local factors on net.

Hence the virtual endowment is:

$$
\tilde{v}_{i}=A_{0}^{T}\left(A_{i}^{T}\right)^{+} v_{i}+u_{i}
$$

where $u_{i}=A_{0}^{T}\left(I-\left(A_{i}^{T}\right)^{+} A_{i}^{T}\right) z_{i}$ is the factor content in the reference country of the difference between the actual output in Country 1 and the particular solution to Eq. (4). Again $u_{i}$ has no factor content in Country $i$, but it may have factor content in the reference.

A country's national income satisfies this relation:

$$
p^{T} y_{i}=p^{T}\left(A_{i}^{T}\right)^{+} v_{i}+p^{T}\left(I-\left(A_{i}^{T}\right)^{+} A_{i}^{T}\right) z_{i}
$$


where again $z_{i}$ is chosen as the difference between the particular solution and the actual local output. Since $A_{i} w_{i}=p$, we may write $p^{T}=w_{i}^{T} A_{i}^{T}$. But then

$$
p^{T}\left(I-\left(A_{i}^{T}\right)^{+} A_{i}^{T}\right) z_{i}=0
$$

since the expression in parentheses projects onto the null space of the $A_{i}^{T}$. The economic intuition is that any output on a flat of the local production possibility frontier has the same national revenue. In other words, the error term in Eq. (5) consists of the factor content in the reference country of a vector of output in Country $i$ that is orthogonal to world prices.

This observation offers a theoretical and empirical advantage. Consider factor prices $w_{0}$ in the reference country. Note that

$$
w_{0}^{T} \tilde{v}_{i}=p^{T}\left(A_{i}^{T}\right)^{+} v_{i}=p^{T} y_{i}
$$

where I have used Eq. (4) and the fact that $w_{0}^{T} A_{0}^{T}=p^{T}$. Hence a country's virtual endowment evaluated at factor prices in the reference country gives its actual GDP.

Let world output be $y=\sum_{i} y_{i}$, and the world's virtual endowment be $\tilde{v}=\sum_{i} \tilde{v}_{i}$. Since the local share of world income is $s_{i}=p^{T} y_{i} / p^{T} y$,

$$
s_{i}=w_{0}^{T} \tilde{v}_{i} / w_{0}^{T} \tilde{v}
$$

If factor prices $w_{0}$ in the reference country are observable, then the actual GDP shares in the world economy can be computed easily from a list of virtual endowments. Hence empirical implementations of these ideas are simple and also theoretically consistent.

We close this section with a fundamental theoretical observation. The transpose of the factor conversion matrix defined in Eq. (2) is the local factor content in Country $j$ of the Rybczynski matrix in Country $i$. It is worth writing this fact explicitly

$$
\left(A_{i}^{+} A_{j}\right)^{T}=A_{j}^{T}\left(A_{i}^{T}\right)^{+}
$$

where I have used the symmetry property of the Moore-Penrose pseudo-inverse $\left(A_{i}^{T}\right)^{+}=\left(A_{i}^{+}\right)^{T}$. In sum, the factor conversion matrix is both the only theoretically cogent way of relating factor prices in Country $j$ with those in Country $i$, and its transpose is the factor content in country $j$ of Country i's Rybczynski matrix.

\section{Examples}

This section will present a sequence of increasingly complicated examples that illustrate the fundamental concepts described above. Each case will consider world economies that consist of two countries. All of my examples will use Leontief technology matrices. But of course, every technology matrix has fixed coefficients when one is only considering small changes in factor prices. Likewise, Rybczynski effects make sense only when goods prices and thus factor prices are fixed. So every one of my examples is more general than will appear at first glance.

\subsection{A Ricardian model}

There are three goods and one factor of production. Let the technology for the first country be

$$
A_{1}=\left[\begin{array}{l}
1 \\
2 \\
3
\end{array}\right]
$$

and that in the second country be

$$
A_{2}=\left[\begin{array}{l}
10 \\
20 \\
30
\end{array}\right]
$$

These technologies were obviously chosen so that every country could produce every good. In particular, no country has comparative advantage in anything, but the first country has an absolute advantage in everything. In particular the intersection of 
the two price diversification cones is the ray in $R^{3}$ generated by the vector $(1,2,3)^{T}$. The transpose of the factor conversion matrix is:

$$
A_{1}^{+} A_{2}=\left[\begin{array}{lll}
1 / 14 & 2 / 14 & 3 / 14
\end{array}\right]\left[\begin{array}{l}
10 \\
20 \\
30
\end{array}\right]=10 .
$$

In other words, wages in the first country are ten times higher than in the second; this fact reflects the productivity differences between countries.

What about the dual of this productivity difference? Consider a marginal increase in the endowment of the first country. It is typical to say that the local Rybczynski effect is not defined because there are more goods than factors. In this case, it does not matter where this extra labor is put to work. In Country 2, the factor content of the marginal output produced in any sector in Country 1 would be ten Country 2 workers.

\subsection{The Textbook $2 \times 2$ model}

Let the technology for the first country be:

$$
A_{1}=\left[\begin{array}{ll}
2 & 1 \\
3 & 1
\end{array}\right]
$$

Again, rows correspond to goods and columns to factors. From now on, the first column corresponds to capital and the second to labor. The first good is locally labor-intensive, and the second is locally capital intensive. The technology for the second country is:

$$
A_{2}=\left[\begin{array}{ll}
20 & 2 \\
30 & 2
\end{array}\right]
$$

where all the variables are analogous.

The transposed factor conversion matrix is

$$
A_{1}^{+} A_{2}=\left[\begin{array}{cc}
-1 & 1 \\
3 & -2
\end{array}\right]\left[\begin{array}{cc}
20 & 2 \\
30 & 2
\end{array}\right]=\left[\begin{array}{cc}
10 & 0 \\
0 & 2
\end{array}\right]
$$

One can read the (local Country 1) Rybczynski effects immediately from $A_{1}^{+}$: capital is an enemy of good 1; and labor is an enemy of good 2. In this simple case, the Moore-Penrose pseudo-inverse is just the usual inverse of the technology matrix. Also, factor prices in Country 2 map into those in Country 1 in the obvious way:

$$
\left[w_{1}\right]=A_{1}^{+} A_{2}\left[w_{2}\right]=\left[\begin{array}{c}
10 w_{2,1} \\
2 w_{2,2}
\end{array}\right]
$$

These are Leontief's factor-specific technology differences, and they are never in the data. ${ }^{2}$

Consider again the dual interpretation of this matrix. Imagine a unit increase in the endowment of capital in Country 1 . Now the Rybczynski effect is unique, and it can be read directly from the first row of $A_{1}^{+}$: the output of the first (locally labor-intensive) sector contracts by one unit; and the output of the second (locally capital-intensive) sector increases by one unit. The local factor content in Country 2 of these output changes 10 units of capital, as it should be.

Now consider Country 1's virtual endowment, when Country 2 is the reference. Let Country 1 have these resources:

$$
v_{1}=\left[\begin{array}{l}
\overline{\mathrm{K}}_{1} \\
\overline{\mathrm{L}}_{1}
\end{array}\right] .
$$

Then its virtual endowment would be:

$$
\tilde{v}_{1}=\left(A_{1}^{+} A_{2}\right)^{T} v_{1}=\left[\begin{array}{c}
10 \overline{\mathrm{K}}_{1} \\
2 \overline{\mathrm{L}}_{1}
\end{array}\right]
$$

In fact, these are the endowment adjustments that Trefler (1993) posited. It is obvious that each unit of capital in Country 1 is ten times as productive as a unit of capital in Country 2; likewise, workers in Country 1 are twice as productive as those in Country 2 .

\footnotetext{
${ }^{2}$ Maskus and Nishioka (2009) find evidence of factor-augmenting technical differences that are correlated with factor endowments.
} 
I hope I have convinced you that the factor conversion matrix makes sense. Now I will introduce an interesting generic theoretical case that is actually typical of the data. No one has ever discussed these kinds of factor differences before. Again, let the technology in the first country be:

$$
A_{1}=\left[\begin{array}{ll}
2 & 1 \\
3 & 1
\end{array}\right]
$$

Now the technology matrix in the second country is:

$$
A_{3}=\left[\begin{array}{ll}
21 & 2 \\
30 & 1
\end{array}\right]
$$

The technology matrix of Country 2 differs only slightly from the first case. ${ }^{3}$ But these minor differences have big practical effects. Now

$$
A_{1}^{+} A_{3}=\left[\begin{array}{cc}
-1 & 1 \\
3 & -2
\end{array}\right]\left[\begin{array}{ll}
21 & 2 \\
30 & 1
\end{array}\right]=\left[\begin{array}{cc}
9 & -1 \\
3 & 4
\end{array}\right]
$$

The small differences in technology have been chosen so that two diversification cones-those for endowments and prices-are large enough so that both countries can produce both goods and employ all their factors. One need not be afraid of the negative offdiagonal element in the factor conversion matrix. For example, if factor prices in Country 2 are $w_{2}=(0.1,0.5)^{T}$, then goods prices are $p=(3.1,3.5)^{T}$ and factor prices in Country 1 are $w_{1}=(0.4,2.3)^{T}$ Since these linear mapping are continuous, there is an open set of goods prices such that factor prices in both countries are strictly positive. In the first case, capital was seen to be ten times as productive in Country 1; now rents in Country 1 are only four times higher than those in Country 2 . In the first case, wages were twice as high in Country 1; now they are more than four times higher than in Country 2. Fix goods prices. Then small changes in technology gives rise to big changes in factor prices-the magnification effect in a different guise.

How can a seeming increase in the productivity of labor in sector 2 actually result in a measured decrease in the wage in Country 2 relative to that in Country 1 ? The answer is that factor-specific productivity comparisons only make sense in very special cases. These cases are not at all generic in theory, and they do not hold in the data.

For a trade theorist it is natural to recognize that measured labor productivity actually depends on the general equilibrium structure of the economy. The difference between the first and the second cases in this subsection is that capital becomes slightly less productive and labor slightly more productive. Hence total factor productivity has decreased in sector 1 and increased in sector 2 in the trading partner. An increase in total factor productivity is identical to a local price increase for that sector, since more revenue is earned with the same factor inputs. Thus the factor prices effects in Country 2 combine two Stolper-Samuleson effects: (1) a decrease in the local wage and an increase in the local rentals rate because TFP has decreased in the labor-intensive sector 1; and (2) a reinforcing decrease in the wage and increase in the rentals rate because total TFP in sector 2-the capital-intensive sector-has increased. The whole empirical literature on testing the Heckscher-Ohlin model has ignored these kinds of effects.

Let us end this sub-section with an illustration of the virtual endowment of Country 1 . Again Country 2 is the reference. Now Country 1 's virtual endowment is:

$$
\tilde{v}_{1}=\left(A_{1}^{+} A_{2}\right)^{T} v_{1}=\left[\begin{array}{c}
9 \overline{\mathrm{K}}_{1}+3 \overline{\mathrm{L}}_{1} \\
-\overline{\mathrm{K}}_{1}+4 \overline{\mathrm{L}}_{1}
\end{array}\right] .
$$

Again the off-diagonal element in the factor conversion matrix might be worrisome. But, for any endowment of Country 1 in its diversification cone, the capital labor ratio is between two and three. So the second element of this virtual endowment is always positive. For example, if $v_{1}=(250,100)^{T}$, then $\tilde{v}_{1}=(2550,150)^{T}$. These endowment adjustments are what Leontief (1953) was searching for.

\subsection{The real world}

In almost all empirical applications, the number of goods exceeds the number of factors, and there are at least two factors. Here is the simplest such case. Technology in the first country is

$$
A_{1}=\left[\begin{array}{ll}
1 & 1 \\
2 & 1 \\
3 & 1
\end{array}\right] .
$$

\footnotetext{
${ }^{3}$ There are many topologies on the space of matrices, and each is induced by a vector norm. The 1-norm focuses on differences in factor-specific productivities, the $\infty$-norm on total factor productivity by industry, and the 2-norm (the spectral norm) and the Frobenius norms focus on aspects of both kinds of technical differences. In this case $\left\|A_{2}-A_{3}\right\|_{1}=1,\left\|A_{2}-A_{3}\right\|_{\infty}=1$, and $\left\|A_{2}-A_{3}\right\|_{2}=1$. On the other hand, $\left\|A_{1}-A_{2}\right\|_{2} \approx 32.5$ so the slight difference between $A_{2}$ and $A_{3}$ is well within the usual measurement error.
} 
and technology in the second country is:

$$
A_{2}=\left[\begin{array}{cc}
1 & 0.5 \\
1 & 1 \\
2 & 1
\end{array}\right]
$$

These technologies were chosen so that goods prices $p=(2,3,4)^{T}$ lies in the intersection of their price cones. The unique local factor prices that correspond to these goods prices are $w_{1}=(1,1)^{T}$ and $w_{2}=(1,2)^{T}$.

The factor conversion matrix is

$$
A_{1}^{+} A_{2}=\left[\begin{array}{ccc}
-1 / 2 & 0 & 1 / 2 \\
4 / 3 & 1 / 3 & -2 / 3
\end{array}\right]\left[\begin{array}{cc}
1 & 1 / 2 \\
1 & 1 \\
2 & 1
\end{array}\right]=\left[\begin{array}{cc}
1 / 2 & 1 / 4 \\
1 / 3 & 1 / 3
\end{array}\right]
$$

Fisher and Marshall (in press) call the transpose of $A_{1}^{+}$the Rybczynski matrix for Country 1. It is obvious that capital is the local friend of sector 3 and the local enemy of sector 1. It is also clear that labor is the local friend of the two most locally labor-intensive sectors and the enemy of the most capital-intensive one. I hope it does not do too much violence to a theoretical purist to call this one element of the supply correspondence the Rybczynsi matrix for this country. Using the duality of the Stolper-Samuelson and Rybczynski matrices implicit in the Hessian of the national revenue function, my colleague and I make this argument more precisely in Fisher and Marshall (in press).

The factor conversion matrix itself is not too controversial, since all of its elements are positive. But I would be remiss not to emphasize again the two central points of this paper: (1) factor-specific productivity differences do not make sense in general; and (2) this matrix is the unique linear mapping that describes factor productivity differences for all goods prices in the intersection of the two price diversification cones.

It is easy to check that

$$
w_{1}=\left[\begin{array}{l}
1 \\
1
\end{array}\right]=A_{1}^{+} A_{2} w_{2}=\left[\begin{array}{ll}
1 / 2 & 1 / 4 \\
1 / 3 & 1 / 3
\end{array}\right]\left[\begin{array}{l}
1 \\
2
\end{array}\right]
$$

Again, let Country 2 be reference. Then the virtual endowment of Country 1 is:

$$
\tilde{v}_{1}=\left[\begin{array}{l}
\overline{\mathrm{K}}_{1} / 2+\overline{\mathrm{L}}_{1} / 3 \\
\overline{\mathrm{K}}_{1} / 4+\overline{\mathrm{L}}_{1} / 3
\end{array}\right]
$$

This virtual endowment confirms that both capital and labor seem to be less productive in Country 1 than in Country 2 .

Let me close this section with a controversial example. Assume now that prices change to $p=(1.98,3,4)^{T}$; thus the prices of the first good has fallen slightly. This price vector no longer lies in the price diversification cone for County 1 . Classical trade theory reminds us that there is a discontinuous output response: Some sector must shut down. Perhaps different sectors shut down in different countries because their technologies are not identical. But in practice, all sectors in every country continue to operate. How can this be?

What local factor prices are a "best guess" for those that would allow this phenomenon to occur? These are given by:

$$
\hat{w}_{1}=A_{1}^{+} p \approx\left[\begin{array}{c}
1.01 \\
0.973
\end{array}\right]
$$

In fact $\hat{p}_{1}=A_{1} \hat{w}_{1} \approx(1.98,2.99,4.00)^{T}$ is the vector lying in the column space of Country 1 's technology matrix that is closest to the actual price vector. It is just the least squares projection of this vector onto the price diversification cone in Country 1 . The two elements of $\hat{w}_{1}$ are the OLS estimates of the rental rate and wage rate that would best rationalize the observed data on technology and goods prices!

The "best guess" is a local Stolper-Samuelson effect. The world price of the locally label-intensive good fell by $1 \%$. The local wage fell by $2.7 \%$ while local rents rose by $1 \%$. Thus changes in world prices correspond to the usual understanding of a Stolper-Samuelson effect for local prices in the price diversification cone that are very near the new world prices.

I chose this price change for a reason. It corresponds to a $1 \%$ increase in the total factor productivity of the first sector in Country 2, a large country whose factor prices are fixed. Hence the new world prices lie in the price diversification cone of the new technology matrix for that country. (Nominal factor prices are still $w_{2}=(1,2)^{T}$, but real income in Country 2 has risen because the output of good 1 has increased.) Thus the factor conversion matrix $A_{1}^{+} A_{2}$ is the best guess for the local Stolper-Samuelson effects in Country 1 of sector-specific technical progress in Country 2. These are akin to the effects Harrigan (1997) described.

\section{Conclusion}

This paper has argued that factor conversion matrices are a computationally simple and theoretically elegant way of comparing factor productivities differences when countries have different technologies. The Factor Price Equalization Theorem has been the 
Achilles' heel of trade theory for too long. But Heckscher-Ohlin theory does not really depend upon it. One can speak about factor content, as long as one has a proper way of comparing factors across countries. Defining productivity-adjusted factors or "effective" factors is neither theoretically generic nor empirically accurate.

The factor conversion matrix is the local factor content of the foreign Rybczynksi effects. Its transpose is the unique linear mapping that translates local factor prices into foreign ones for all world prices in the intersection of the price diversification cones.

Fisher and Marshall (2008)already have applied these ideas empirically to good effect. Once one admits that the most banal form of Heckscher-Ohlin theory does not fit the data, one has to come up with a new theoretical prediction. ${ }^{4}$ That prediction has to deal forthrightly with adjustments to factor productivities across countries. I know this is a harsh statement, but I have shown clearly here that one can make appropriate theoretical predictions using factor conversion matrices. For example, robust tests using virtual endowments have already verified all these ancillary assumptions: (1) constant returns to scale; (2) goods prices are equalized across countries; (3) there is no home bias in consumption; (4) preferences are identical and homothetic; (5) there is no home bias in consumption; and (6) it is not necessary to assume that some goods are not traded.

Once one appreciates that Heckscher-Ohlin theory applies to local technologies, one can make appropriate empirical predictions. Skill-biased technical change may raise wages of the local skilled workers and raise wages of the unskilled workers abroad. Likewise the process of capital accumulation in one country may increase the share of heavy industry in the local economy but decrease it abroad. Development paths are country-specific, not universal.

\section{References}

Berhhofen, D. M. (2009, November). Multiple cones, factor price differences and the factor content of trade. Journal of International Economics, 79(2), $266-271$. Brecher, R. A., \& Choudhri, E. U. (1982, May). The factor content of international trade without factor-price equalization. Journal of International Economics, 12(3-4), $277-283$.

Chipman, J. S. (1969, October). Factor price equalization and the Stolper-Samuelson theorem. International Economic Review, 10 (3), $399-406$.

Choi, Y. -S., \& Krishna, P. (2004, August). The factor content of bilateral trade: An empirical test. Journal of Political Economy, 112 (4), 887-914.

Davis, D. R., \& Weinstein, D. E. (2001, December). An account of global factor trade. American Economic Review, 91(5), 1423-1453.

Fisher, E. O., Marshall, K. G., 2008. The factor content of trade when countries have different technologies. Unpublished manuscript http://www.calpoly.edu/ efisher/FCT.pdf

Fisher, E.O., Marshall, K.G., in press. The structure of the American economy. Review of International Economics.

Gale, D., \& Nikaido, H. (1965, April). The Jacobian matrix and global univalence of mappings. Mathematische Annalen, 159(2), 81-93.

Hallak, J. C. (2006, May). Product quality and the direction of trade. Journal of International Economics, 68(1), 238-265.

Harrigan, J. (1997, September). Technology, factor supplies, and international specialization: estimating the neocassical model. American Economic Review, 84(4), 475-494.

Helpman, E. (1984, March). The factor content of foreign trade. The Economic Journal, 94(373), 84-94.

Leontief, W. (1953, September). Domestic production and foreign trade: The American capital position re-examined. Proceedings. American Philosophical Society, 97(4), 332-349.

Maskus, K. E., \& Nishioka, S. (2009, April). Development-related biases in factor productivities and the HOV model of trade. Canadian Journal of Economics/Revue Canadienne d'Économique, 42(2), 519-553.

Romalis, J. (2004, March). Factor proportions and the structure of commodity trade. American Economic Review, 94(1), 67-97.

Samuelson, P. A. (1953). Prices of factors and goods in general equilibrium. Review of Economic Studies, 21(1), 1-20.

Schott, P. K. (2003, June). One size fits all? Heckscher-Ohlin specialization in global production. American Economic Review, 93(3), 686-708.

Schott, P. K. (2004, May). Across-product versus within-product specialization in international trade. Quarterly Journal of Economics, 119(2), 647-678.

Trefler, D. (1993, December). International factor price differences: Leontief was right! Journal of Political Economy, 101 (6), 961 -987.

\footnotetext{
${ }^{4}$ The work of Choi and Krishna (2004)is a step in the right direction, but Berhhofen (2009) casts doubt on their exact empirical findings.
} 